\title{
O FILHO DO HANSENIANO EM FACE DA INFECÇÃO LEPROSA
}

\author{
DR. OTAVIO GONZAGA
}

\section{TUBERCULOSE E LEPRA QUANTO À DESCENDÊNCIA}

Conhecem-se as semelhanças morfologicas estre os bacilos de ambas as moléstias. Durante muito tempo foi dogma a existência das "Heredodistrofias tuberculosas". E chegaram alguns autores a aceitar a tuberculose, não ùnicamente como uma causa geral de distrofias diversas mas também como uma causa específica. E em relação aos recém-nascidos apontaram-se os casos de "desnutrição progressiva", e de "mortes inexplicáveis" descritos por vultos eminentes. da eścola médica francesa. Afirmou-se a frequência dos abortos nas mulheres tuberculosas, e a de recém-nascidos hipotróficos, condenados à atrepsia. E os que, anos adeante, escapavam das enfermidades. próprias da infância, caminhavam para o infantilismo, para a debilidade, para a própria tuberculose. Fez-se a revisão do assunto. Os. pediatras afirmam a raridade das lesões cardíacas congênitas nas crianças filhas de tuberculosos, o infantilismo se refugiou nas desordens funcionais endocrínicas, o raquitismo, doença de carência, cortou as suas amarras com a tuberculose. As investigações de DeBRé. e Laplane, citadas por Maurice PÉhu e André Dufourt acusam em 127 crianças de mães tuberculosas o pêso médio de nascimento de 3.089 gramas. O crescimento dessas crianças foi satisfatório em $70 \%$ dos casos. Só se observou $8 \%$ de crescimentos defeituosos. Apenas $13 \%$ faleceram de debilidade congênita e de atrepsia. Temse de reconhecer que êstes algarismos não se afastam muito do que se daria com um mesmo número de crianças tomadas ao acaso. "Em relação às taras congênitas em 300 lactentes nascidos de tuberculosas encontraram os referidos autores apenas quatro casos: um pé chato, um lábio leporino e duas cardiopatias" Em uma estatística sôbre o desenvolvimento físico dos pupilos da obra de Grancher, de preservação da infância contra a tuberculose F. Houssay dá as seguintes porcentagens :

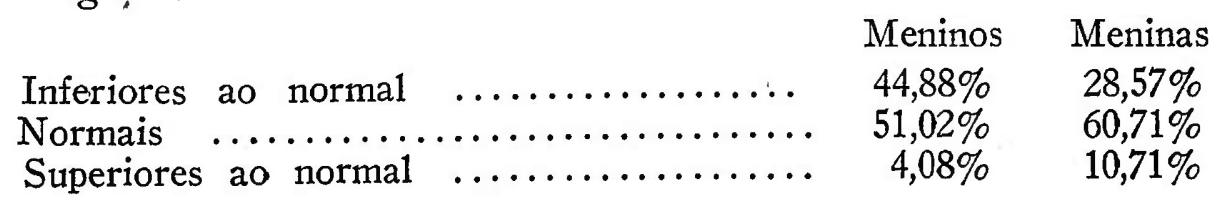


Mesmo, na controvérsia, aceita a existência das "heredo-distrofias tuberculosas" no conceito de Couvelaire de que "os recém-nascidos de mães tuberculosas trazem para a vida uma vitalidade diminuída" não podemos asseverar que a lepra tenha o mesmo caráter específico. No nosso quadro de 100 recém-nascidos temos as porcentagens de $45 \%$ de pesos acima de 3.200 grs. e $28 \%$ de debilidade congênita de um modo geral, sendo apenas de $3 \%$ a forma grave (abaixo de $2 \mathrm{ks}$.). Quanto à estatura, $85 \%$ de talhes normais. Lisongeiras se apresentam também as curvas do desenvolvimento ponderal e estatural aos 12 meses, aos 5 e 10 anos, como se vê dos quadros respectivos.

$\mathrm{Na}$ tuberculose é incontestável que se o bacilo de $\mathrm{Koch}$ é causa indispensável da infecção, êle não basta para determinar a enfermidade desde que the faltem condições favoráveis de terreno, que se resume na constituição individual. A infecção se dá independentemente da constituição, mas é esta que, mais do que razões hereditárias, estado geral e influência de moléstias intercorrentes, preside a marcha da tuberculose, nos limites de simples infecção ou nos moldes de moléstia declarada. Em resumo, da constituição depende o futuro da tuberculose na criança. Trata-se em frente do bacilo de modalidades de uma resistência ou fraqueza natural, ambas de ordem constitucional. Infelizmente não possuímos ainda um método capaz de medir ou de nos orientar sôbre essa resistência natural, como a reação de Schick para a diftéria, e a de Dick para a anti-toxina estreptocócica. Procura-se atribuir a defesa contra a tuberculose a uma produção mais ativa de anticorpos por conta de uma hiper-atividade celular produtora de uma maior quantidade de anticorpos. Recìprocamente a fraqueza em face da infecção se explicaria por deficiência do sistema retículo-histiocitário e portanto capacidade diminuída na fixação dos gérmes e formação de anticorpos. É uma questão apenas de disergia funcional do sistema retículo endotelial. E para esta disergia funcional não parece influir a herança no sentido da tuberculose. Crianças sadias, com ascendentes absolutamente sãos em relação à tuberculose, sofrem a infecção, do mesmo mọo que o fazem as crianças filhas de tuberculosos. No campo experimental já se provou que carneiros vindos de três gerações tuberculosas não acusaram nenhuma disposição específica, portando-se em frente da infecção tuberculosa da mesma maneira do que os outros descendentes de animais sãos. Parece, em resumo, que a criança embora não herdando a tuberculose, herde a constituição que juntamente com a infecção e outras causas supervenientes farão dela uma criança tuberculosa. Não se pode avançar que a infecção esteja em relação com a constituição mas parece que existe uma relação entre esta e a marcha daquela no organismo. Só o fator constitucional pode explicar as variantes por vêzes incompreensíveis da tuberculose infantil.

E se nas crianças tuberculosas, como afirma Pende predomina o biotipo da constituição astênica, com característica diminuição da to- 
nacidade dos ligamentos, quer seja o indivíduo longilíneo ou brevelíneo, não notamos nenhuma particularidade morfológica constitucional, entre os filhos dos lázaros, quer entre os que foram preservados da doença quer entre os que a contraíram exclusivamente em virtude da convivência com os doentes, antes de internados no Asilo. Aliás já Kusnetzow, citado por Bernardinel.l estudando em 100 casos a importância da "Constituição na Etiologia da Lepra "chegou a uma conclusão negativa sôbre a predominância, entre êles, de determinado biotipo. Notamos uma elevada porcentagem de "diátese exsudativa" com sintomas mucosos catarrais, maximé durante a primeira e segunda infância, colimando muitos, por volta dos cinco e sete anos, com a extração de amígdalas e adenóides. Mas não se pode de forma alguma atribuir a êste fato um caráter específico de anomalia constitucional hereditária por conta da lepra. Em tôdas as clínicas, públicas ou particulares, conhecem os pediatras a frequência, cada vez maior, de crianças com sintomas de "diátese exsudativa", quer esta seja considerada, na opinião de CzERNY, seu criador, uma "verdadeira doença" ou como querem outros apenas "uma predisposição para adoecer"

\section{LEPRA E ANOMALIAS CONSTITUCIONAIS HEREDITÁRIAS}

\section{a) Dentição. b) Moléstias infecciosas}

Entre as 644 criạças que até esta data passaram pelo Asilo nas várias idades, não foi assinalado nenhum caso de deformações congênitas e degenerações múltiplas. Aliás MURPHy estudando no obituário de Filadélfia 890 casos de mortalidade e mortinatalidade, com certificados de deformação congênita, absolutamente conifirmados, não pôde descobrir nenhuma relação com as enfermidades crônicas da mãe do mornento da concepção, concluindo que quanto mais idade tinha a mãe mais probabilidade havia de dar à luz um filho congênitamente disforme. No's casos em aprêço a mais elevada idade materna foi de 43 anos, a mais baixa de 17, predominando a maioria das idades das mães entre 20 a 40 anos. (80\% dos casos).

Tivemos apenas um. caso de "idiotia mongolóide" e cinco casos de hipotiriose frusta. Nenhum caso de diabete ou obesidade. Nenhum caso de lesões cardíacas congênitas. Apenas um caso de "moléstia mitral" em uma menina falecida.aos 14 anos por conta de um reumatismo manifestado aos 9 anos. Um óbito de "anemia aplástica" em menina de 16 anos, recolhida com 11 anos, em precárias condições de saúde e com Wasserman positivo. Um óbito de "tuberculose" aos 12 anos em menina recolhida em precaríssimo estado de saúde: 5 quilos aos 11 meses e que veiu a falecer em sanatório de tuberculose. E como nota curiosa em 641 internados, durante treze anos, apenas um caso de "apendicite" confirmado cirùrgicamente, 
fato que faz pensar no número de apêndices extirpados por conta das sugestões dos ambientes familiares...

Por sua vez, os filhos dos lázaros não mostram nenhuma aptidão mórbida que se possa atribuir a um caráter específico da doença dos pais. O mesmo sucede no seu desenvolvimento psicológico, estático e dinâmico. São crianças como as outras crianças. Não nos parece. ássim certo, sem embargo da autoridade de que se reveste, o conceito de During: "A lepra dos pais pode produzir entre as crianças uma diminuição de vitalidade, por uma menor resistência às diversas infecções, notadamente a tuberculose". Ao contrário, não revelaram absolutamente uma "menor resistência" às infecções os casos de sarampo (130 casos), coqueluche (116 casos), varicela (20 casos), parotidite (144 casos), difteria ( 6 casos), polimielite ( 1 caso), surgidos no Asilo.

A lepra dos pais não exerce nenhuma influência sôbre a dentição dos filhos. Em 347 exames em crianças até os 18 anos, o dentista. do Asilo sr. J. DE Souza Frota conclue que "não há nenhuma influência lesiva à integridade do sistema dentário nos filhos dos leprosos, por conta do mal dos pais". Num total de 902 intervenções em dentes temporários e permanentes houve apenas 16,6\% de extrações.

Reconhece DuRING, no citado trabalho que "não parece que as crianças, filhas de leprosos, tenham suscetilidade de contrair a lepra. A hereditariedade atávica de uma doença infecciosa, como a lepra, é um contrasenso..." Não agiram também as moléstias infecciosas como "causas reacionais" a que se refere MUIR e que podem, enfraquecendo momentâneamente a resistência do organismo, numa fase a que corresponde maior número de bacilos, provocar manifestações clínicas da lepra incubada e que, sem essas causas temporárias e sem as causas permanentes (sífilis, paludismo, verminoses, perturbações intestinais crônicas e desconfồrto) poderia curar-se por si mesma..." Seria o mesmo aspecto da tuberculose: lepra infecção e lepra moléstia.

\section{LEPRA E INFECC̨õES TRANSPLACENTÁRIAS, IMUNIDADE CONGENITA PASSIVA, TRANSITORIA}

Chegamos aquí ao discutido problema do papel da infecção materna sôbre o feto. "Para aceitá-la é importante, acentúam AlPERS e Patten., considerar o critério em que esta transmissão é aceita a saber: provas bacteriológicas e, mesmo na sua falta a presença da moléstia ao nascimento, a têrmo, prematuro, vivo ou morto". A transmissão através da placenta, aceita como uma complicação rara em um restrito número de moléstias, vem sendo admitida como mais frequente do que se pensava. Avoluma-se a sua lista e apontam-se casos indiscutíveis na tuberculose, infecções estreptocócicas, gonocócicas, 
pneumocócicas, pielite, sarampo, escarlatina, febre tifóide, varíola, malária e anquilostomose, que passamos a resumir.

Em relação à tuberculose congênita Withman e Grene fazendo a revisão dos casos relatados de 1922 a 1936, mencionam 113 casos autênticos de tuberculose pré-natal e 519 dúvidosos, na seguinte maneira:

Congênita tuberculose do feto e da placenta .........

Bacilos tuberculosos mas sem modificações histológicas:

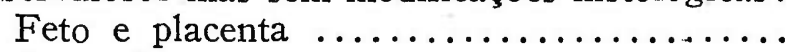

Feto sòmente $\ldots \ldots \ldots \ldots \ldots \ldots \ldots \ldots \ldots \ldots$.

Bacilos tuberculosos no feto com tubérculos histo-

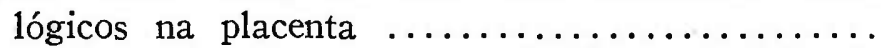

Tuberculose da placenta com bacilos e tubérculos

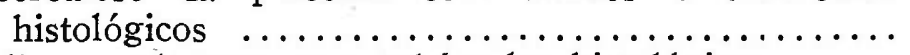

Bacilos na placenta, sem tubérculos histológicos ......

\begin{tabular}{cc} 
Autênticos & Duvidosos \\
38 & 509 \\
21 & 10 \\
3 & - \\
4 & - \\
44 & - \\
3 & - \\
\hline 113 & 519
\end{tabular}

O problema da presença da tuberculose no feto sem sinais da doença foi explanado por Calmette, Valtis e Lacomme no estudo de 10 recém-nascidos de mães tuberculosas e que forneceram inoculações positivas em cobaias. Injeções do sangue do cordão umbelical também deram, em vários casos, lesões tuberculosas em cobaias nas experimentações de MoncKeberg e Vergara. A mesma evidência é apresentada por Levy-Solal e sèus colaboradores no caso de um recém-nascido de mãe tuberculosa falecido com dois dias de vida. Não se provou a evidência da tuberculose da placenta e das vísceras, mas a inoculação do material dos gânglios mesentéricos e traqueobrônquicos ocasionou a tuberculose experimental. Outros exemplos poderiam ser citados no mesmo sentido, mas a sua raridade retira tôda a importância da transmissão congênita da tuberculose entre as causas da natimortalidade.

A ocorrência da infecção estreptocócica no recém-nascido era considerada muito rara antes da comunicação, em 1933, de DurHam relatando entre 39 casos de septicemia materna 15 casos de septicemia do recém-nascido, sendo que em 8 estiveram os sintomas presentes por ocasião do nascimento. A infecção estafilocócica é incluída entre as causas de abortos por De. LeE e Curtis.

Se bem que em vários casos relatados a transmissão transplacentária da artrite gonocócica em recém-nascidos deva ser mais atribuída à infecção durante o parto, aparecem casos, aliás raros, de infecção intrauterina, como, entre outros, os três casos de poliartrite mencionados por Slobozianu e Hercovici. O peneumococo pode também ser transmitido da mãe ao feto. BECARDIt, GoRdon e LedErer, Anderson e Pohl relatam casos de penumonia em fetos abortados e en recém-nascidos de mães com septicemia pneumocócica, comprovados todos pela necropsia ou pela cultura do sangue de ambas, mãe e filho. WARVIck relata o caso de um recém-nascido que 
viveu apenas duas horas e meia, revelando a necropsia uma típica bronco-pneumonia. BRowne relata o caso de um recém-nascido que viveu apenas oito horas, mostrando a necropsia um derrame pleural e uma pneumonia já em estado de hepatização cinzenta.

Reinou certa controvérsia sôbre a transmissão transplacentária da escarlatina, mas não deixam dúvida sôbre a sua evidência vários casos descritos, entre outros, por De LeE, LIdDel e Le BeUf de recém-nascidos com descamação típica. Duskes e Dodge relatam um caso de difteria transplacentária; com abôrto em meio da gravidez, revelando a necropsia do feto massas de bacilos diftéricos na cavidade peritonial e na superfície do fígado. Göry e DALSACE citam reações positivas em fetos de gestantes com febre tifóide. Graham relata seis casos de pielite em recém-nascidos, sendo em um indiscutível a origem intra-uterina da infecção. Pesquisadores alemães citados por AlPers-Patten relatam antraz transmitido pela mãe,- sendo os bacilos encontrados nas placentas e nos fetos. A lista da transmissão placentária do virus do sarampo não é grande, mas. não resta dúvida. que a moléstia pode, em certas condições, passar da mãe ao fetoNouvat apresentou uma relação de 82 casos coletados até 1904. Debré, JoAnnon e Marianai relatam cinco casos de sarampo congênito, dividindo-os em dois tipos: o prénatal e postnatal em que o recém-nascido mostra evidência de que a infecção se iniciou dentro do útero. É incontestável que também a varíola pode ser transmitida através da placenta, como prova o aparecimento da erupção no primeiro e segundo dia de vida do recém-nascido. LyNcH fez em 1932. a revisão do assunto desde a primeira descoberta de Epstein em 1932.

Várias são as citações da transmissão da malária da mãe ao feto. O primeiro e mais extensivo estudo foi feito por Weselko: observações origináis de 200 casos de malária congênita, sendo que em 187 houve provas hematológicas positivas. Muito convincentes são os casos em que os parasitas são encontrados logo após o nascimento, horas após o parto, como os casos relatados por Winslow, DumoLARD e VIALlet. Plasmódios foram encontrados por Blacklock e GoRDon em 37\% de placentas de mães sofrendo de malária.

Longe já vai o tempo em que se pensava que a placenta era um filtro perfeito para todo o elemento figurado, de uma perféição de que não se aproxima nenhum filtro artificial. Sabe-se hoje que não sòmente virus filtráveis, mas ainda outros micro-orgañismos, bactérias ou protozoários, são também capazes de atravessar essa barreira e infetar o feto dentro do útero. O que, entretanto, escreve G. LAVIER "é menos geralmente conhecido é que parasitas maiores e de esestrutura singularmente mais complicada, os vermes intestinais, podem comportar-se da mesma maneira" $\mathrm{E}$ o fato se explica fàcilmente, levando-se em conta as migrações. efetuadas através dos órgãos, antes de alcançarem o lugar definitivo do seu parasitismo, pelas larvas de pequenas dimensões. A infestação congênita não pode ser 
assim observada em todas as espécies. O que determina a sua possibilidade, e também a frequência da sua realização, é o ciclo evolutivo próprio a cada verme, variável em amplitude e em direção. As. verminoses não se apresentam exatamente como as outras infecções congênitas. A infestação fetal precisa ser contemporânea da infestação materna. É preciso que esta se realize em período ainda de larvas circulantes no organismo materno. $E$ quando se pensa no forte poder de penetração das larvas, que em quatro minutos podem atravessar um revestimento tão resistente como a pele, compreendese fàcilmente a possibilidade delas atravessarem, por via sanguínea, a placenta, passando para a circulação fetal. Mas não podem tornar-se adultas no feto, ficam em estado de vida latente até o nascimento quando, iniciada a respiraçã̃o, elas abordam o pulmão e seguem o seu conhecido ciclo. E assim a anquilostomose congênita foi confirmada. e reproduzida experimentalmente. Howland em 1917 encontrou ovos de anquilóstomos em fézes de uma criança de 14 dias, fato que levou Adler e Clark e posteriormente Foster a reproduzirem a infestação congênita de filhotes de cadelas grávidas, experimentalmente infetadas.

Haverá também na lepra a infecção clandestina congênita, transplacentária? CHRISTIAN referindo-se aos bacilos encontrados por vários invèstigadores, SugAR (1913), Chujo (1916), Rodrigues (1926), Pineda (1927), no feto, cordão umbelical e placenta, conclue: "A experiência geral dos que trabalham nos leprosários é que se as crianças são separadas dos pais infetantes logo após o nascimento, só uma desprezível proporção desenvolve a lepra” No leprosário de Molokai, refere BERNy “em 109 crianças transferidas ràpidamente fora da colônia, nenhuma se tornou leprosa, ao passo que entre as que permaneceram junto às mães $56 \%$ foi a porcèntagem de infecção."

Êste fato, comprovado aliás pela experiência do Asilo sôbre 644 crianças, em 13 anos, mostra que a mãe leprosa não transmite ao filho em rélação à moléstia uma imunidade hereditária pròpriamente dita. Mas não deixa de conferir-lhe nos primeiros meses de vida, como nas outras moléstias infecciosas, uma imunidade congênita passiva e transitória, propriedade comum a todos os recém-nascidos durante os primeiros meses de super-atividade celular e visceral. " $\mathrm{O}$ lactente, em definitivo, resume GERMAINe Dreyfús SÉE apresenta durante os seis primeiros meses da vida, e em menos grau até um ano, modos de defesa bem particulares, um passivo humoral, outro ativo e tissular e que, enxertado transitòriamente sôbre um terreno. constitucional hereditário durável, conferem à sua patologia uma fisionomia muito especial, uma individualidade biológica bem diferente da do adulto" Data dos primeiros trabalhos de EHRLICH, em 1892, as experiências sôbre camondongos imunizados contra venenos vegetais, o conhecimento da imunidade congênita passiva e que mostra que só a mãe transmite a proteção passageira, cuja passagem se faz 
por via dupla, transplacentária principal e mamária acessória. Com excepção de algumas experiências discordantes, mas isoladas, a maior parte das observações confirmou as conclusões de EHRLrcH. Recentemente investigações biológicas sôbre a passagem das aglutininas com dosagem comparativa no sangue do coridão e no sangue materno forneceram resultados igualmente provantes. $E$ por fim as numerosas provas clínicas concordam com observações experimentais baseadas sôbre o estudo das diversas epidemias de moléstias infecciosas e da ausência da contaminação dos lactentes cujos pais são doentes. Só esta imunidade congênita passiva pode explicar a raridade da infecção leprosa, excepcional nos primeiros meses entre tais lactentes. A reconhecida deficiência dos processos ativos de defesa constitue um estado de miopragia constitucional e compreende-se assim que as infecções possam tornar-se ràpidamente intensas e generalizadas na infância, desde o momento em que a criança passa a fazer o seu próprio sangue. O recém-nascido desenvolve com dificuldade sua imunidade humoral e só fabrica anticorpos com parcimônia. E só a imunidade congênita passiva e transitória, simples transferência da mãe ao filho, pode explicar a menor porcentagem da lepra nos primeiros meses da vida. Em uma estatística fornecida em 1936 pelo Serviço de Profilaxia da Lepra do Estado de S. Paulo em 2.006 casos até a idade de vinte anos, encontraram Otávio Gonzaga e Oscar MonTEIRo DE BARros apenas 2 casos de idade de menos de um ano.

\section{suswwswswaws :}

\section{CARDIOSCLEROL TONICO CARDIACO ATOXICO \\ HIPERTENÇÃO ARTERIAL - MIOCARDITES - ARTERIOESCLEROSE $A$ base de Viscum album - Cactus grandiflora - Cratoegus - Kola - Scila - Rodanato de Potassa \\ Amostras e literaturas a disposição dos srs. Medicos}

CAIXA, 4500 
e estimulo à celula nervosa

\section{Nergofon \\ hexapentanolcarboxil-hipotosfito de cálcio}

encerrando $35 \mathrm{mg}$ de fósforo elementar por ampôla de 2 cmc., em combinação organocálcica, exerce essa dupla ação de maneira rápida e duradoura.

\section{AMOSTRAS}

disposição dos Srs. Médicos
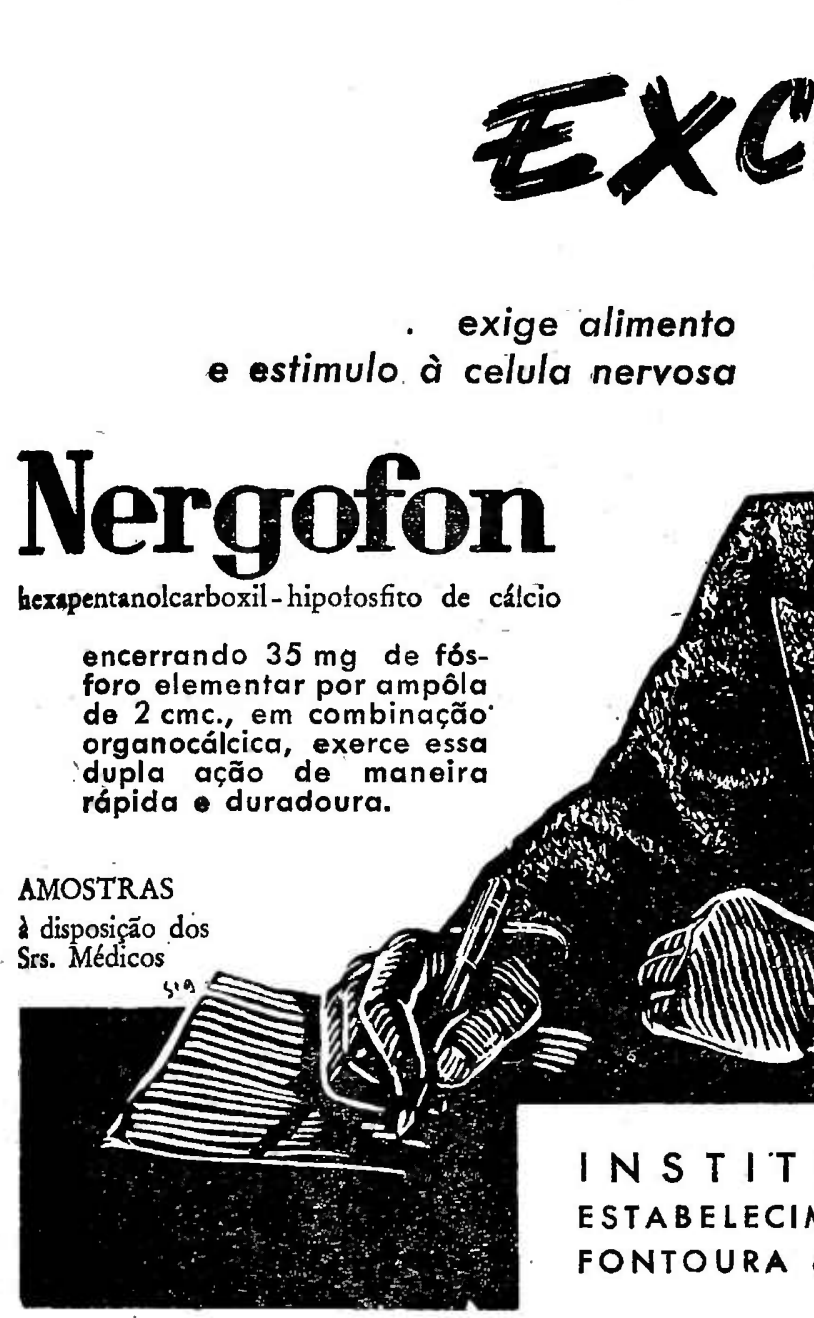

exige alimento

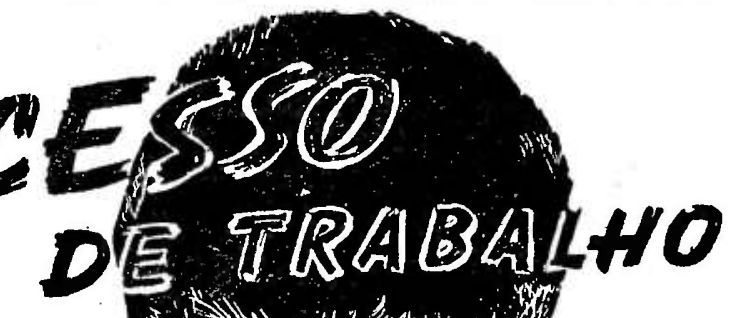




\section{PYORRHÉA}

Gengivas sangrentas, dentes abalados e mau halito: Resultados positivos em 8 dias, com o especifico PYORRHON.

CONSULTAS: $30 \$ 000$.

DEMONSTRAÇÓES PRATICAS AOS SENHORES MEDICOS E DENTISTAS.

\section{DR. CLINEO PAIM}

Rua Barão de Itapetininga, 120 $5 .^{\circ}$ andar Salas, 505 e 506 (Casa Guatapará)

Tel: 4-4050 SÃO PAULO

\section{ENDOSCOPIOS}

PARA TODOS

OSCASOS DE

DIAGNOSTICA

E CIRURGIA

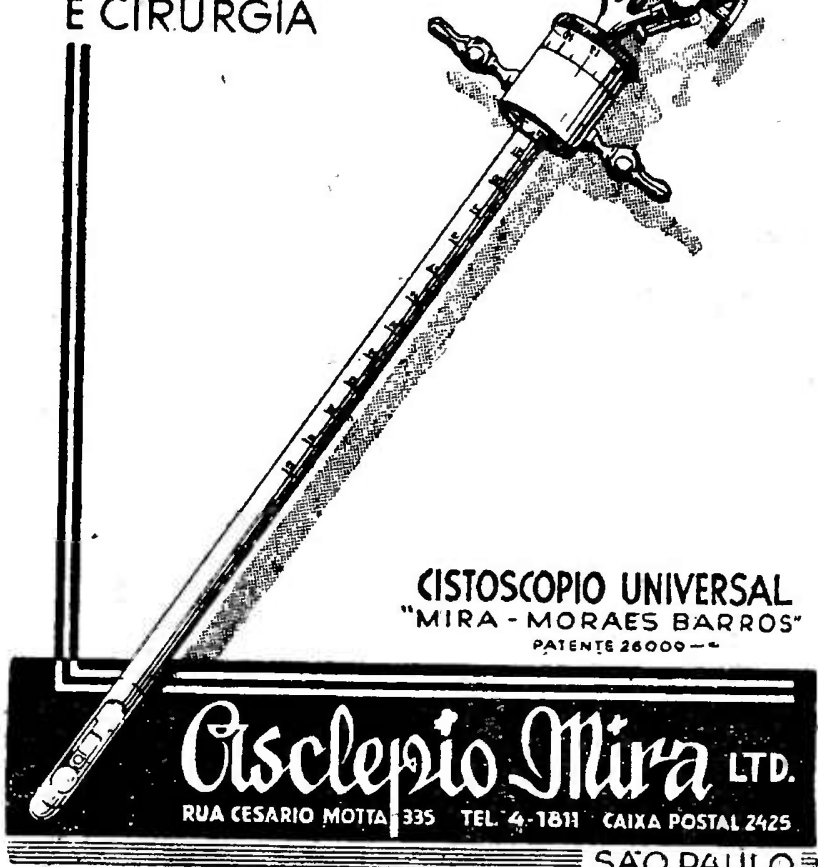

\section{Pyorrhon}

Un medicamento que veio resolver os casos de Gengivites \& Pyorhiée

\section{A T E S T A D O}

E' para mim um prazer atestar que venho empregando em minha clinica com os mais brilhantes resultados, o Pyorrhon, medicamento de escol para o tratamento da Piorrhéa Alveolar e das Gengivites.

Tambem venho calorosamente recomendando o seu uso aos meus pacientes, porque assim fazendo estes teem assegurada a perfeita saude do seu meio bucal.

O Pyorrhon é um preparado que pela propaganda honesta com que é lançado e pelos seus meritos, merece da nossa classe a melhor acolhida.

São Paulo, 6 de Outubro de 1939.

Octavio Demacq Rosas.

Receite PYORRHON aos seus clientes 